\title{
Interpreting The Learning Styles Of Traditional And Distance Learning Students
}

Marian C. Schultz, (E-mail: mschultz@uwf.edu), University of West Florida James T. Schultz, (E-mail: james.schultz@erau.edu), Embry Riddle Aeronautical University

\begin{abstract}
The emergence of telecommunication technologies has generated innovative strategies resulting in online education competing for student enrollment. Learning is no longer restricted by space and time, and has become more reliant on empowerment rather than confinement. This study sought to determine if the use of the Kolb Learning Style Inventory (LSI) could be used to determine which learning style(s) best reflect the traditional learner, and which are representative of the distance learning student. The study placed respondents into one of four styles, depending on how they responded to the Inventory: Diverger, Assimilator, Accommodator, and Converger. The study then compared responses within and between the groups to test for significance. It found that while there was significance between all of the groups except the Accommodator/Converger, the only group which had significance within was the group with the Assimilator style.
\end{abstract}

\section{Introduction}

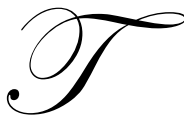

he emergence of telecommunication technologies has generated innovative teaching techniques which have resulted in strategies which have brought about online education as a means of competing for student enrollment. Learning is no longer restricted by space and time, and has become more reliant on empowerment rather than confinement. "Virtual" or "electronic" classrooms promote learning by offering instruction that can be accessed by students from their various locations, often in their own time, and responded to in ways that are meaningful to them. Web-based education offers flexibility and time; ownership of learning and understanding; cost effectiveness; accessibility and equal opportunity. However, it can be restrictive in lieu of time required to learn the new process; self directed effort in both learning and understanding can be difficult to achieve; and there may be an inability to access the materials (Minotti, 2003). For many years now there has been a growing discussion on whether the online learning environment is suitable for everyone.

The U.S. Department of Education reports that in 1995, 58\% of community, junior, and technical colleges were offering distance learning classes, a number that is expected to reach $86 \%$ in 2006 . International Data Corporation reports that by 2005, training delivered over the internet is expected to reach $42 \%$ of the information technology market (Dugan, 1998). In 1968, Dubin and Taveggia published The Teaching Learning Paradox: A Comparative Analysis of College Teaching Methods, where they demonstrated that no particular method of college instruction is measurably better than another when evaluated by student examination performance. The method of instruction chosen did not affect student performance (Keegen, 2000). Numerous studies indicate that the learning outcomes of distance education students are similar to the learning outcomes of traditional on-campus students.

While increases in enrollments translate to additional funds for higher education, retention and student success in pursuing web-based instruction are also considered measurements of program effectiveness. Similarly, the ability to predict which students would be interested in taking online instruction would be useful in scheduling and hiring the faculty needed to instruct these courses. It is believed that student performance in distance learning and traditional classes may be directly related to how students learn. 


\section{Learning Models For Web-Based Education}

The "convenience education" format integrating the internet is frequently referred to as Web-Based Education (WBE). While there are different approaches and variations to WBE, most follow one of two primary models. The "mass-market" model delivers materials to students primarily relying on "one way" delivery, leading to limited one-to-one communication between the student and the instructor. Web pages often replace video for lectures, and email replaces postal mail for student-teacher correspondence. This approach creates an institutional advantage by financially streamlining the impact of accommodating hundreds, or even thousands of students in a single course. A fairly "cheap" form of education can be offered through inexpensive adjuncts that can be hired to do the grading and communication (Kirka, 1996).

The "learning-focused" model utilizes technology to create a learning community similar to a graduate seminar, as a collaborative exchange environment where the faculty member serves as a facilitator creating the structure for the exchange. This environment limits the number of students who can be successfully accommodated in such a "learning network" format (Harasim, Hiltz, Teles \& Turoff, 1994).

The major advantages of WBE, convenience and self directed pace, are balanced with the disadvantages of bandwidth or timely feedback frustration. The missing "social presence" of the professor and classmates may impact the motivational strength of the student, subsequently reversing the possible advantages of flexibility in both time and location. This is related to passive and active approaches to learning.

\section{Collaborative Learning And Web-Based Education}

Passive approaches to learning assume that students learn by receiving and assimilating knowledge individually, independent from others (Bouton \& Garth, 1983). In contrast, active approaches present learning as a social process which takes place through communication with others (Mead, 1994). The learner actively constructs knowledge by formulating ideas into words, and these ideas are built upon through reactions and responses of others (Bouton \& Garth, 1983; Alavi, 1994). In other words, learning is not only active but also interactive. Collaborative learning is fundamentally different from the traditional "direct-transfer" or "one-way knowledge transmission" model in which the instructor is the only source of knowledge or skills. In collaborative learning, instruction is learner-centered rather than teacher-centered and knowledge is viewed as a social construct, facilitated by peer interaction, evaluation and cooperation. This conception of learning shifts the focus away from the teacher-student interaction and toward the role of peer relationships (Johnson, 2001). Learning is enhanced when interaction is perceived to be collaborative and not competitive.

\section{Studies On Web-Based Education}

There have been several studies conducted to determine the appropriate focus for WBE. Ocker and Yaverbaum conducted a study at Pennsylvania State University which explored the effects of two modes of collaboration on student groups. The findings indicate that asynchronous collaboration is as effective as face-to-face collaboration in terms of learning, quality of solution, solution content, and satisfaction with the solution quality. However, students were significantly less satisfied with the asynchronous learning experience, both in terms of the group interaction process and the quality of group discussions (Ocker \& Yaverbaum, 2000). It is believed that students will choose a learning platform that supports their satisfaction with the total process.

The New Jersey Institute of Technology studied sections taught by the same instructor, utilizing the various delivery methodologies of traditional face-to-face, distance mode of all video, and a combination of face-to-face and video conferencing (VC). Generally, the results of these subjective evaluations were positive. For example: Over half of the students in the VC and video experimental sections felt that they were able to complete more courses than would have otherwise been possible, leading to faster progress toward their degree; the majority of students felt that the VC improved the convenience of course access (73\%), access to their professors (65\%), and the quality of learning (58\%); active participation online by both faculty and students, and the use of group or collaborative learning strategies in online learning environments are positively related to desirable outcomes by both students and 
faculty; outcomes as measured by grades in the courses show no significant differences between modes. Course grades are only weakly correlated with most variables measured, except for overall grade point average. Although the degree of perceived collaborative learning in the course correlates significantly with perceived outcomes, correlation is not causation (Bouton \& Garth, 1993).

Several studies have shown that collaborative learning strategies result in greater student involvement with the course and more engagement in the learning process (Hiltz, 1999). Collaborative learning methods are also more effective than traditional methods in promoting student learning and achievement (Johnson, 1981), and enhance student satisfaction with the learning and classroom experience.

\section{Connecticut Distance Learning Consortium}

In 1979, Connecticut was the first state to initiate a learning consortium to promote online learning and teaching and ensure its quality. The Connecticut Distance Learning Consortium (CTDLC) studied 32 institutions, collecting data from spring 1998 through fall 2000, utilizing 140 online courses and 2,500 students. It sought to identify various personality traits essential to a prime online learning environment. Questionnaires consisted of both demographic inquiries, as well as open ended. The form tracked reasons that students offered for enrolling in online courses over the traditional classroom and served as a course evaluation. Students reported that regardless of the difficulty, size and course requirements, the professor was perceived to hold the sole responsibility for formatting “.... an online teaching environment which favors thoughtful communication, requires the active participation of teachers and students, and above all promotes learning" (Goldsmith, 2002). This study, based on 400 student responses, sought to determine whether there was anything in the online environment that made it easier for students to learn, achieve their goals, or participate in class discussions. Similarly, it sought to identify any factors that increased the difficulty level for students in the online format (Goldsmith). Over $90 \%$ of the respondents indicated that they would enroll in another online class.

A study, reported in The American Journal of Distance Education, compared two different sections of the same course (Neuhauser, 2002). One section was taught online and the other was taught in the traditional classroom during the same academic semester. The factors that were used in the comparison were gender, age, learning styles, multimedia familiarity, task and course effectiveness, and examination grades. Both sections were taught by the same professor and incorporated the same instructional materials. The study showed that exam and project scores, participation levels, and final grades were not statistically significant between the two sections, although the average scores for the online class were slightly higher. Approximately $96 \%$ of the online students reported that they thought the course was either as effective or more effective in their learning process than previous face-to-face courses that they had completed. "There were no significant differences between learning preferences and styles and grades in either group. "The study showed that equivalent learning activities can be equally effective for online and face-to-face learners" (Neuhauser, 2002, p. 99).

In another study reported in The American Journal of Distance Education, the results were very similar when comparing the same course taught both on-campus and online (Aragon, Johnson \& Shaik, 2002). The traditional classroom and online students were very similar in age, year of baccalaureate completion, GPA, and work experience. "However, they did vary significantly on 1 of the 10 scales at the task engagement level (study aids) and on 3 of the 4 scales at the cognitive controls level (reflective observation, abstract conceptualization, and active experimentation)" (Aragon, Johnson \& Shaik, 2002, p. 227). The study acknowledged that the online students were more active in reflective observation (learning by watching and listening) and abstract conceptualization (learning by thinking) because the online environment required students to use these methods of learning. Face-to-face students were more active in active experimentation (learning by doing). These facts tend to suggest that individuals who are more adept at reflective observation and abstract conceptualization may be more comfortable in an online learning environment, and those that favor using active experimentation may be more comfortable in a classroom setting.

Another study examined the personalities and demographics of students who enrolled in a university class and had the choice of selecting either a traditional on-campus class or online class to complete the course (Mattes, 
Nanney \& Coussons-Read, 2003). The personality profiles of the students were determined utilizing the $5^{\text {th }}$ of the 16 Personality Factor (16PF) questionnaire. This test assesses 16 primary personality characteristics and 5 global personality factors. "Students taking online classes scored higher than on-campus students on scales of abstract reasoning and apprehension and lower on the scale for social boldness. Online students were also more comfortable with computers than on-campus students, and were more likely to be nontraditional students ( 26 and older)" (Mattes et al, p. 85). Without considering gender, this study found that online students reported significantly lower scores for extroversion, which is one of the five global personality factors (Mattes et al, p. 99). However, when gender was considered, it was found that the tendency for extroversion in the online class was due to gender. All female students (online and classroom) scored closely in the personality characteristics of extroversion and self-reliance. However, male online students were less extroverted and more self-reliant than the male on-campus students. In other studies, "computer classes tend to be male dominated, and that females in the academic field of computers possessed more masculine qualities and that more masculine qualities in men and women are correlated with lower computer anxiety" (Mattes et al, p. 99).

\section{How Is Quality Measured In Web-Based Education?}

Everyone involved in taking, producing, and delivering online learning would agree that quality is paramount; however, objectively measuring quality is difficult and infrequently undertaken. Poor design, project under funding, overly optimistic schedules, and technical barriers are all adversaries of quality. A methodical approach to evaluation can help remove subjective biases and achieve a more authoritative analysis (Kirka, 1996). Research has focused on characteristics that are associated with successful distance learners. Personality type has been suggested as the most dominant factor in the effective criteria for success in distance learning programs. Sexton states, "...the motivation to learn comes from within. External incentives and rewards can help, but they can't make up for a lack of personal desire for knowledge and growth" (2000). He further specifies six items that help to determine success in distance learning as it pertains to personality type:

- $\quad$ Self directed learners work with an underlying sense of purpose.

- $\quad$ Self directed learners never surrender the art of dreaming and re-dreaming or setting and achieving goals.

- $\quad$ Self directed learners focus on their gifts. They value their unique talents and skills, and leverage their strengths and manage their weaknesses.

- $\quad$ Self directed learners see themselves as volunteers, not victims. They generally have an internal locus of control.

- $\quad$ Self directed learners act despite their fears. They generally have a high tolerance of ambiguity.

- $\quad$ Self directed learners thrive on interdependence. Generally, not the long ranger type, they trust and rely upon others (Sexton, 2000).

Creative instructional design can encourage the user to contemplate an idea, leading to an effective method of mental interaction. The design goal should be to encourage intellectual interaction with the training information, not simply include lots of bells and whistles. Interactions should always test informational skills and cognition, or they should activate more information the student can use to advance learning (Brown, 2003).

Another factor in developing WBE programs is to design products that adapt to the users' abilities and intelligently respond to their input. If the user is having difficulty with one concept or task, offer remediation through extra information presentation and reinforcement or suggest alternative resources (other courses, publications, or hyper-linked information). It is important to provide meaningful feedback to the user that reinforces a concept and hardens the foundation for further learning (Brown, 2003).

A sound WBE program design will reject linear thinking and abandon vertical design. A highly structured, top down approach to instructional design does not address the needs and preferences of most students. Finally, in WBE design especially long load times for insignificant information are annoying; make every bit of downloaded information count (Brown, 2003). Frequent student-faculty interaction helps to build student motivation and participation. The frequency and immediacy of feedback to the students is critical to student perception of course appeal. E-learning standards promise and deliver interoperability as well as reusability, durability, and accessibility 
(Brown). Leaders within the U.S. Department of Defense saw a need to fuse a number of more narrow specifications into an all encompassing standard for next generation online learning. The Advanced Distributed Learning (ADL) initiative in 1997 built upon the work of other initiatives and defined new specifications to glue everything together. The result is the Sharable Content Object Reference Model (SCORM) which is a model for defining, packaging, and managing learning objectives.

The flexibility in both study time and location were touted as the critical attractions toward online courses. Another deciding factor in the success of the online format lies in the student attitude. The student's attitude must demonstrate dedication and commitment, as well as be focused on attention to detail. Most classrooms use asynchronous course conferences and threaded discussions for team learning which plays a large part in developing students' attitudes towards online education. Students often are more inclined to participate when they perceive themselves to be faceless in the communication arena. The increase in communication and understanding of material may be instrumental in building student self esteem and confidence. Again, the visual anonymity may support increased levels of honesty in exchanging personal information. Students reported concern for studentteacher interaction and poor writing or typing skills as reasons for avoiding online courses. It is apparent that some extroverted personalities may crave the face-to-face interaction obtained in the normal classroom setting. Research concludes that there is a cluster of personality characteristics that seem to accompany learners whom prefer and succeed in distance learning. These characteristics include autonomy, tolerance for ambiguity, flexibility, and an internal locus of control (Thompson, 1998).

\section{Kolb's Learning Style Model}

Learning style is also a very important criterion for success in the distance-learning environment. Kolb's learning style model classifies learners as having a preference for concrete experience or abstract conceptualization in how learners take in information. Kolb's model further classifies learners with a preference for active experimentation or reflective observation in describing how learners internalize information (Conner, 2003). Subsequently, these combinations of learning preferences result in four potential types of styles.

- Divergent Style: (Concrete Experience, Reflective Observation) The focus of this style resides with the imagination and value awareness. These individuals are capable of viewing situations from diverse perspectives. These individuals integrate brainstorming strategies which emphasize social interaction. These learners respond well to explanations of how course material relates to their experience, their interests, and their future careers. The instructor should function as a motivator.

- Assimilator Style: (Abstract Conceptualization, Reflective Observation) This style focuses on the ability to create models by integrating disparate information into full explanations. This style focuses less on people and emphasizes the abstract ideas. These learners respond to information presented in an organized, logical fashion and benefit if they have time for reflection. The instructor should function as an expert.

- Convergent Style: (Abstract conceptualization, Active Experimentation) The greatest strength for this style lies in problem solving, decision making and the practical application of ideas. These learners do well in situations where there is a single correct answer. These learners choose technical tasks over interpersonal situations. These learners respond to having opportunities to work actively on well-defined tasks and to learn by trial-and-error in an environment that allows them to fail safely. The instructor should function as a coach, providing guided practice and feedback.

- $\quad$ Accommodator Style: (Concrete Experience, Active Experimentation) These learners enjoy implementing plans and experiencing innovative situations. These learners like applying course material in new situations to solve real problems. The instructor should stay out of the way, maximizing opportunities for the students to discover things for themselves (Conner, 2003).

This study sought to determine if the use of the learning style inventory (LSI) could be used to determine which learning style(s) best reflect the traditional learner, and which are representative of the distance learning student. The Kolb Learning Style Inventory is a self-descriptive test, based on experiential learning theory that is designed to measure the strengths and weaknesses of a learner in the four stages of the learning process. According to the LSI there are four different learning modes: concrete experience (CE), students must be able to involve 
themselves fully and openly without bias in new experiences; reflective observation (RO), students must be able to reflect on and observe experiences from many perspectives; abstract conceptualization (AC), students must be able to create concepts and integrate observations into logically sound theories; and active experimentation (AE) students must be able to use theories to make decisions and solve problems (Osland, Kolb \& Rubin, 2001).

The LSI measures a student's emphasis on the four learning modes by asking them to rank order a series of four words that describes the four different abilities. An example of a series of words and the learning mode which they reflect would be feeling (CE), watching (RO), thinking (AC) and doing (AE). Combination scores then indicate the extent the student emphasizes abstractness over concreteness and active experimentation over reflection (AERO) (Osland, Kolb \& Rubin, 2001). While the LSI does not measure an individual's learning style with $100 \%$ accuracy, it presents an indication of how an individual sees themselves as a learner.

This study sought to determine how students perceive themselves as learners, and to determine whether there was a significant relationship between their learning style, and their preferences for traditional classroom courses over distance online courses. In conducting this study students were first asked to take the learning style inventory (Osland, Kolb, \& Rubin 2001). After their learning styles were calculated into a single data point that combines the scores of the four basic modes, the students were given a survey which asked their perception of how well they learn in both distance learning and traditional classes. Students who had not participated in both modes of learning were excluded from the study. The survey asked students if they believed they learned better in traditional or distance learning classes, or if they perceived no difference between the two.

The data received from the surveys were quantified to determine if there was a significant difference between the learning style and type of delivery methodology. A one-dimensional Chi Square test was conducted to ascertain if there was significance between the responses within each individual learning style. The results of the four Chi-Square tests revealed the following:

\section{Accommodator}

Yes 20

No 12

Chi-Square 2.00

Critical Value@.05 3.84

Assimilator

Yes 8

No 40

Chi-Square $\quad 28.57$

Critical Value @.05 $\quad 3.84$

\section{Converger}

Yes 28

No 20

Chi-Square $\quad 1.33$

Critical Value @.05 3.84

\section{Diverger}

Yes 44

No 64

Chi-Square $\quad 3.70$

Critical Value@.05 3.84

Only individuals with the Assimilator learning style had significant difference on whether they would take a Distance Learning course. In the case of this group, over $83 \%$ of the individuals responded "No" to the question as to whether they would take a Distance Learning course. 
Two-dimensional Chi-Square tests were then conducted between the four groups to see if there were significant differences between the groups. The results of the Chi-Square tests revealed the following:

\section{Accommodator/Assimilator}

Yes 20

No 12

Chi-Square

Critical Value@.05

$\begin{array}{ll}\text { Yes } & 8 \\ \text { No } & 40 \\ & 17.73 \\ & 3.84\end{array}$

\section{Accommodator/Converger}

Yes 20

No 12

Chi-Square

Critical Value@.05

$\begin{array}{ll}\text { Yes } & 28 \\ \text { No } & 20 \\ & .139 \\ & 3.84\end{array}$

\section{Accommodator/Diverger}

Yes 20

No 12

Chi-Square

Critical Value@.05

$\begin{array}{ll}\text { Yes } & 44 \\ \text { No } & 64 \\ & 4.71 \\ & 3.84\end{array}$

\section{Assimilator/Converger}

Yes 8

No 40

Chi-Square

Critical Value

$\begin{array}{ll}\text { Yes } & 28 \\ \text { No } & 20 \\ & 17.78 \\ & 3.84\end{array}$

\section{Assimilator/Diverger}

Yes 8

No 40

Chi-Square

Critical Value@.05

$\begin{array}{ll}\text { Yes } & 44 \\ \text { No } & 64 \\ & 8.67 \\ & 3.84\end{array}$

\section{Converger/Diverger}

Yes 28

No 20

Chi-Square

Critical Value@.05

$\begin{array}{ll}\text { Yes } & 44 \\ \text { No } & 64 \\ & 4.14 \\ & 3.84\end{array}$

The Chi-Square tests revealed that there was significance in five of the six quantifications. Only the Accommodator/Converger revealed no significance.

A Chi-Square test was also conducted between the students who identified their gender to ascertain whether significance existed between those who would take a Distance Learning course, and those who would not. The sample size was not sufficiently large enough to allow the four learning styles to be compared to each other on a gender basis. Results from the Chi-Square test revealed the following:

\section{Male}

Yes $\quad 56$

No 18

Chi-Square

Critical Value @.05

\section{Female}

Yes 48

No 92 
The results of the Chi-Square test revealed a significant difference between the male and female students responding to the question. Only $34 \%$ of the females responding to the question stated that they would take an online course, as compared to $74 \%$ of the males.

\section{Conclusions}

Kolb (2001) suggests that the Accommodator learning style is best suited for distance learning. While this study found that Accommodators and Convergers are the most receptive to distance learning courses, there was no significant difference, between the responses favoring traditional verses on-line courses, in either group. The same was true for Divergers, even though the majority of respondents in this group favored the traditional delivery method. The respondents with the Assimilator learning style were the only group which had a significance difference within the group. The Assimilators significantly favored traditional over distance learning courses.

Significance was also found between all of the styles except the Accommodator/Converger styles. In both of these styles the number of individuals favoring the distance learning courses exceeded those selecting the traditional delivery method. This was the opposite in the other two groups where the traditional style was favored over distance learning courses. In the comparison between males and females respondents, males significantly favored distance learning courses over female respondents. This supports previous studies which showed that males were more likely to favor computer courses than females.

\section{References}

1. Alvai, M. (June, 1998). "Computer-Mediated Collaborative Learning: An Empirical Evaluation”, MIS Quarterly, pp. 150-174.

2. Aragon, S., Johnson, S., \& Shaik, N. (2002). "The influence of learning style preferences on student success in online versus face-to-face environments", The American Journal of Distance Education, Vol 16, No 4, pp. 227-244.

3. Brown, M. P. (2003). "Technology as an Instructional Tool”, Retrieved November 3, 2003 from http://ericacve.org/mp_brown_02.asp

4. Bouton, C. and Garth, R.Y. (1993). Learning in Groups. New Jersey Technical Institute Working Paper.

5. Conner, Marcia L. (June 8, 2003) Introduction to Learning Styles. Ageless Learner. Available http://agelesslearnerner.com/backg/lstyleintro.html.

6. Dugan, S. (1998) "Will Jini Grant Sun's Wish?”, Retrieved November 3, 2003 from http://www.javaworld.com/jw-10-1998/jw-10-iw-jinitest.html.

7. Goldsmith, D. (Summer 2001). "Communication Humor and Personality: Students attitudes to online learning", [online]. Available: http:// www.ctdlc.org/evaluate/humorpaper.pdf

8. Harism, L., Hiltz, S.R., Teles, L., \& Turoff, M., 1994. Learning Networks: A Field Guide to Teaching and Learning Online. Cambridge, MA: MIT Press.

9. Hiltz, S.R., \& Benbunan-Fich, R. Evaluating the Importance of Collaborative Learning in Online Education.

10. Johnson, D.W. (2001). Student-Student Interaction: The Neglected Variable in Education. Vol. 10, N.1, pp. 5-10.

11. Keegan, Desmond. (2000) Distance Training: Taking Stock at a Time of Change. London: RoutledgeFalmer.

12. Kirka, S. (1996). "Distance Learning, the Internet, and the World Wide Web", ERIC Digest. Retrieved November 3, 2003 from the ERIC database.

13. Mattes, C., Nanney, R., \& Coussons-Read, M. (2003). "The online university: Who are its students and how are they unique?" Journal of Educational Computing Research, Vol. 28, No 2, pp. 89-102.

14. Mead, G.H. (1994). Mind, Self and Society. Chicago, U. of Chicago Press.

15. Minotti, J., \& Giguere, P. (June 2003) "The Realities of Web-Based Training", T.H.E. Journal 30 (11), pp. 41-44.

16. Ocker, R.J, \& Yaverbaum, G. J. (2000). Computer-Mediated Communication versus Face-to-Face Collaboration: Results on Student Learning, Quality and Satisfaction. Pennsylvania State University. 
17. Sexton, G. (2000). "Learner, Direct Thyself”, Line Zine. Available:

http://linezine.com/2.1/features/gsldt.htm.

18. Thompson, M. M. (1998). "Distance learners in higher education”, In Gibson, Chere Campbell, Distance Learning in Higher Education; Institutional Responses For Quality Outcomes. Madison, WI: Atwood Publishing, pp. 9-25.

Notes 
Notes 